\title{
Outcomes of involuntary psychiatric commitment: An integrative review
}

\author{
Mohammed Hamdan Alshammari ${ }^{1}$, Rizal Angelo Natoza Grande*1, Ghedeir M. Alshammari ${ }^{2}$ \\ ${ }^{1}$ Department of Mental Health Nursing, College of Nursing, University of Hail, Hail City, Kingdom of Saudi Arabia \\ ${ }^{2}$ Metabolic Disorders Laboratory, Food Science and Nutrition Department, College of Food and Agricultural Sciences, King \\ Saud University, Riyadh, Kingdom of Saudi Arabia
}

Received: February 25, 2017

DOI: $10.5430 /$ cns.v5n3p10
Accepted: May 31, 2017

Online Published: June 2, 2017

\begin{abstract}
Psychiatric commitment has been a central subject in mental health care. It has been surrounded with ethical and legal issues basically focusing on individual's autonomy and legal rights. This review aimed to explore the outcomes of psychiatric commitment on the lives of the individuals subject to this intervention despite these legal and ethical issues. Outcomes of involuntary commitment were leaning more towards its risks on individuals but poses benefits on health system and society. Therefore, more qualitative and quantitative studies focusing on benefits of psychiatric commitment are needed.
\end{abstract}

Key Words: Psychiatric commitment, Involuntary admission, Commitment ethical issues, Commitment legal issues

\section{INTRODUCTION}

Psychiatric commitment has been a central subject in mental health care as numerous studies and reviews continue to discuss and debate on the potential benefits and risks of psychiatric commitment. Definitions and inclusion criteria of psychiatric commitment vary across countries depending on the legal standards established. ${ }^{[1]}$ In China, the Mental Health Law of 2007 stated that an individual may be handled by hospitalization for medical protection by a guardian or family if he/she is evaluated to be in need of hospitalization but refused to comply and if he/she poses danger on himself/herself or the public. ${ }^{[2]}$

There were three approved criteria for involuntary detention or admission namely, harm to self, harm to others and inability to care for self. ${ }^{[3]}$ What has been the long-time common criteria is mentioned in the study by Lin-Ying $\mathrm{H}$, which are: (1) threat to others due to psychiatric illness, and (2) threat to self in terms of suicide or self-care deficit. ${ }^{[2]}$ Stulz et al. ${ }^{[4]}$ further listed several patient variables which include severity of symptoms, psychotic symptoms like hallucinations and delusions, potential harm to self and/or others, suicidal tendencies, alcohol and substance abuse, previous hospitalizations, self-care deficit, among others. Though these criteria may be valid, the "dangerousness" criteria have been under series of discussions due to the lack of definite and clear standards on its measure and the people involved in evaluating such criteria. ${ }^{[5]}$

Methods in implementing psychiatric commitment include consideration of individual's autonomy, and decision-making powers or referrals which may follow mandates that place the power to decide to non-medical authorities such as judges, courts, government officials, or social workers as well as family or significant others and decisions of the mental health professionals according to legal provisions. ${ }^{[6]}$ Bola and col-

\footnotetext{
${ }^{*}$ Correspondence: Rizal Angelo Natoza Grande, EdD; Email: dr.ragrande@gmail.com; Address: Department of Mental Health Nursing, College of Nursing, University of Hail, Hail City, Kingdom of Saudi Arabia.
} 
leagues' study ${ }^{[7]}$ in South Korea revealed that more than half (66\%-77\%) of involuntary admissions were referred primarily by the family while Rotvold and Wynn ${ }^{[8]}$ accounted $25 \%$ in their study. Family involvement in the involuntary admission of the patient may pose long-term consequences in terms of relationship with the patient. ${ }^{[9]}$

In terms of the power of authorities, $\operatorname{Ran}^{[10]}$ reported a case of a man who was involuntarily admitted to a psychiatric hospital for six and a half years due to the township government's plea to have him sent to a mental hospital as the man constantly tried to sue the local government about a mistreatment of a disabled woman. The man was diagnosed as "litigious paranoia" and went under electronic shock treatment, tried to escape and made suicide attempts. The case reached the public knowledge and was reinvestigated leading to the dismissal of the town officials involved due to misuse of their power to produce a fake certificate stating that the man had a certain mental illness. While individuals subject to this treatment should be central in the plan of care, this case displays a deviation from upholding an individual's rights. ${ }^{[11]}$

Given these points, it has remained a challenge for authorities and mental health professionals to continue its implementation because of its limitations due to the variety of issues such as legal, mental, social issues accompanying as it has been seen to lean more towards reducing risks on the patient and individuals around him/her more than alleviating symptoms and producing therapeutic effects. ${ }^{[12]}$ A patientcentered, recovery-oriented practice should be applied in implementing this intervention to upholding rights of individuals subject to involuntary commitment. ${ }^{[13]}$ Thus, this review aimed to explore the outcomes of psychiatric commitment on the lives of the individuals involved in such intervention despite legal and ethical issues.

\section{Methodology}

Studies on psychiatric commitment were searched through the electronic databases Proquest, CINAHL, PubMed and Medline Plus. The descriptors that were used to locate the articles include "psychiatric commitment", "involuntary commitment", civil commitment", "outcomes of involuntary commitment" and were limited to English text only. The inclusion criteria were that the studies should have been published from 2007 until present, those that allowed full text access and full research articles relevant to the outcomes of psychiatric commitment and matches with the purpose of this integrative review. In the initial search there were 100 studies meeting the keywords, and from the initial reading of the articles and checking it against the focus of this study, they were trimmed down to 40 . Another round of reading and checking were employed to determine if the study matches accurately with the main objectives that lead to a final number of 12 studies (see Figure 1).

Upon identification of all studies, analysis of the articles was done to classify which are focused on the outcomes of psychiatric commitment and those that are not and were based on the inclusion criteria and the objectives of this review. Evaluation of these articles was based on the article title and their abstracts. Should the title and abstract provided limited overview of the whole study for selection, a review of the full article was done. Analysis and synthesis of data extracted from the classified articles were done in a descriptive manner. The process used in this methodology was based on the framework used in an integrative research review by Whittemore and Knafl ${ }^{[14]}$ (see Table 1).

\section{Validity and reliability of data procured}

The studies presented in this integrative review were carefully chosen based from a set of guidelines and inclusion criteria such as the date of the studies that should be the latest possible study available from all sources and databases, that the studies should provide complete and accurate information on the focus of this integrative review which is on patient outcomes of involuntary psychiatric commitment and does not repeat and present the same context and finding found in other studies or literatures. During the initial search, the studies underwent analysis and critical review by the authors and suggestions were sought from experts in the field of psychiatric nursing, medical psychiatry and experts in law. Their expert advice and intelligent appraisal of the results of the search resulted to a bias free derived studies, expert evaluated findings and seamless compilation of studies required by this integrative review.

\section{RESULTS AND DISCUSSION}

The search for studies harvested 100 articles of which were searched through the mentioned databases. Out of these articles, 40 studies met the inclusion criteria. The data provided by these studies were compiled, organized by themes noting similarities and differences. After a more and thorough review, 12 studies exactly and completely fit all the protocols and findings needed to include in this study. These studies, reports and cases were derived from ten countries: UK, USA, Canada, Norway, Switzerland, Germany, France, China, South Korea and Brazil (see Table 2).

\subsection{Outcomes of psychiatric commitment 3.1.1 Patient outcomes}

The key towards recovery is facilitating treatment compliance and participation. Outcomes of involuntary hospitalizations 
greatly affect the individual's perception on the treatment. although, there were studies that found the positive aspect of Patient outcomes lean more toward the negative implications this practice.

of implementing involuntary treatment among individuals

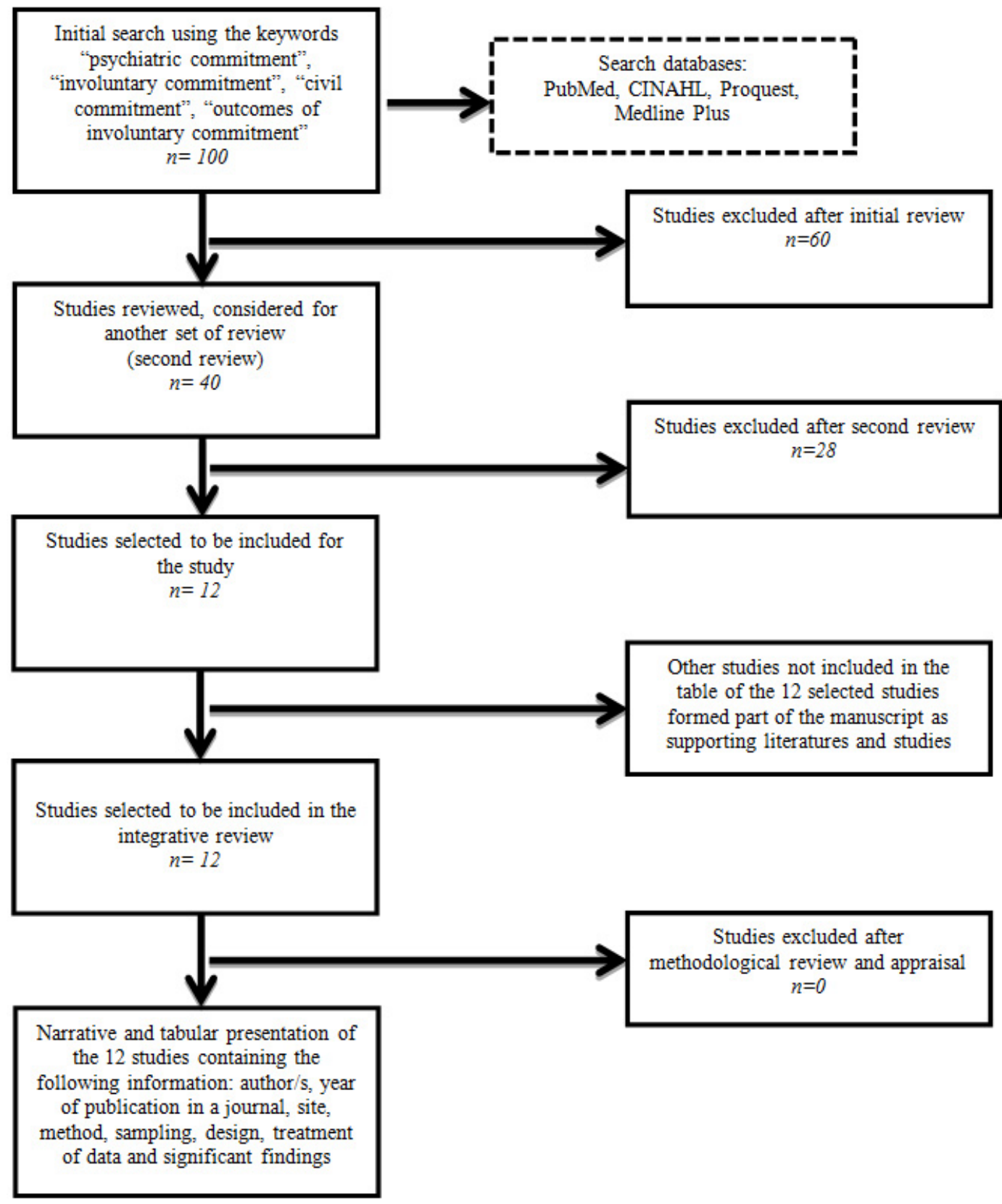

Figure 1. Flowchart of studies selection and derivation of final studies included in the integrative review

In the United Kingdom, a qualitative study by Katasakou et al., ${ }^{[15]}$ the perceptions of those patients who were involuntary hospitalized after the experience were explored. Their perceptions were classified to positive feedback, negative and ambivalent views. Patients who reported positive views on their involuntary hospitalization stated that the said intervention was necessary for them to ensure treatment adherence, prevent further harm and provide opportunity for them to recover in a safe place. Also, they perceive that they were generally unwell to recognize their need for the treatment so they might have refused the treatment therefore, coercive measures were needed. In contrast, patients who perceived that their involuntary hospitalization was not an effective choice for them stated that there could have been more effective and less coercive interventions that should have provided to them as they felt an unjust breach of their autonomy. Those 
patients with ambivalent views on their involuntary hospitalization share the same sentiments as those with positive and negative perspective and stated that they should have stayed less time in the hospital or given other ways to improve his/her mental health status such as exercises, etc. Some studies showed that patients reported satisfaction with their care, had improved attitudes toward treatment and that they felt less coerced in their daily interactions with staff, reduced aggression, cooperation with treatment and improved Global Assessment of Functioning scores. There are also factors that affect patient's experience during involuntary confinement.

Table 1. Framework of Integrative Review as proposed by Whittemore and Knafl ${ }^{[14]}$

\begin{tabular}{|c|c|}
\hline Stage of Review & Illustration of Decisions and Issues \\
\hline Problem identification & $\begin{array}{l}\text { Psychiatric commitment has been a practice in the field psychiatry and mental health nursing for so many years } \\
\text { now, however, it still remained on issue of whose jurisdiction it is. Is it the law, that has the power to uphold or } \\
\text { remove ones civil rights or science that has the knowledge to determine when the mind does not function anymore } \\
\text { as required by society. Though mental disorders are universal phenomena that impact the life and wellbeing of the } \\
\text { affected person, family and even the community at large, geographically and politically, some factors draw the } \\
\text { line between whose authority to control one's freedom and whose intelligence can decide whether someone is } \\
\text { unable to exist to enjoy that freedom. Therefore, literatures, theories, proven and well tested studies, laws, } \\
\text { policies, jurisprudence, statutes, records, databases and all sources available to explain the outcomes of } \\
\text { psychiatric commitment to a person should be sought together with the underlying laws being mandated to some } \\
\text { states, countries and territories on this issue. }\end{array}$ \\
\hline Search & $\begin{array}{l}\text { With a focus in mind on the issue of involuntary psychiatric commitment especially on its outcomes to a person, } \\
\text { the keywords "psychiatric commitment," "involuntary commitment, "civil commitment," "outcomes of } \\
\text { involuntary commitment" were searched from known nursing studies databases such as PubMed, CINAHL, } \\
\text { Proquest and Medline Plus covering the years } 2007-2017 \text { procuring as much as latest studies as possible. Initially, } \\
100 \text { studies were searched and downloaded using the keywords mentioned and with available complete study. } \\
\text { After a more thorough review of the studies and articles while bearing in mind the specific focus of the search, it } \\
\text { was cut down to } 40 \text { studies and eventually to } 12 \text { studies upon a more critical review of them. }\end{array}$ \\
\hline Data Evaluation & $\begin{array}{l}\text { The } 12 \text { studies downloaded that completely suit the needs of this integrative review were carefully read, checked } \\
\text { for further fitness, determined its comparison and contrast to each other without going further away from the main } \\
\text { problem of this integrative review. }\end{array}$ \\
\hline Data Analysis & $\begin{array}{l}\text { All the } 12 \text { studies on involuntary psychiatric commitment are unique in their methods, sampling, data treatment, } \\
\text { results and more importantly findings but their focus is shared. They all discussed the different outcomes as well } \\
\text { as laws and policies that exist within each state and country where these studies were adopted from. These } \\
\text { countries are the USA, UK, Brazil, Canada, China, South Korea, Germany, Switzerland, France and Norway. } \\
\text { Each study was read and re-read, synthesize and checked for accuracy to determine if it discussed the topic at } \\
\text { hand. Other quality checks for validity and reliability were implemented as well by comparing it to other existing } \\
\text { studies and articles that discusses the same context but do not provide needed findings as required by this present } \\
\text { integrative review. }\end{array}$ \\
\hline Presentation & $\begin{array}{l}\text { A synopsis of each study was explained in narrative form in this integrative review so to present diverse practices } \\
\text { and implemented laws of different countries on involuntary psychiatric commitment. More so, its outcomes to } \\
\text { persons affected and who have had the treatment. }\end{array}$ \\
\hline
\end{tabular}

While in Germany, Jendreyschak et al. ${ }^{[16]}$ conducted a retrospective analysis of 10,547 admitted patients from years 2004-2009 in three Child and Adolescent Psychiatric (CAP) hospitals and found out that commitment laws and other legal instruments for regulating involuntary placements are inconsistent and a standardized description or systematic analysis is needed. Their study suggests that the influence of demographic, institutional variables and care and health services aspects should also be investigated as part of a comprehensive psychiatric evaluation of patients admitted in various psychiatric facilities.

In Brazil, as reflected in the study of Casella and Loch ${ }^{[17]}$ religious affiliation was determined as a predictor of involuntary psychiatric admission. The study involved eighty eight patients who were voluntarily admitted and eighty one involuntarily admitted. It was found out that cultural factors related to religious affiliation of the admitted patients might Published by Sciedu Press play an important role in deciding their psychiatric hospitalization legal status. It further revealed the importance of dealing with the subject of religion with patients who are involuntarily admitted in a psychiatric facility.

Another study in the USA, McNiel and colleagues ${ }^{[18]}$ found an association between satisfaction with treatment and less perceived coercion, better working alliance, and decrease levels of psychological reactance, which is consistent with Sheehan and Burns' study findings ${ }^{[19]}$ that patients who were admitted involuntarily had higher proportion of reported high coercion (89\%) as compared with those who were voluntarily admitted (48\%). To better these factors, the key is active collaboration between the patient and significant others and the health care provider which requires treating patients with respect, honesty, dignity therapeutic relationship, also, maybe enhance through training and supervision of the mental health professionals. 
Table 2. Profile of studies (2007-2017) $(\mathrm{n}=12)$

\begin{tabular}{|c|c|c|c|c|}
\hline & Author, Year, Site & Method, Sampling, Instrument & Design, Treatment of Data & Significant Findings \\
\hline 1 & $\begin{array}{l}\text { Burns, Rugkasa, } \\
\text { Molodynski, Dawson, } \\
\text { Yeeles, Vasquez, Voysey, } \\
\text { Sinclair, Priebe, 2013, } \\
\text { United Kingdom }\end{array}$ & $\begin{array}{l}\text { Random sample of } 442 \text { patients involuntarily admitted } \\
\text { aged } 18-65 \text { years old for a period of one month }\end{array}$ & $\begin{array}{l}\text { Quantitative: randomized } \\
\text { controlled trial using random } \\
\text { assignments }\end{array}$ & $\begin{array}{l}\text { Imposition of compulsory supervision does not reduce the } \\
\text { rate of readmission of psychiatric patients. It does not } \\
\text { support reduction in overall hospital admission to justify } \\
\text { the significant curtailment of patients personal liberty }\end{array}$ \\
\hline 2 & $\begin{array}{l}\text { Stulz, Nevely, Hilpert, } \\
\text { Bielinski, Spisla, Maeck, } \\
\text { Hepp, 2014, Switzerland }\end{array}$ & $\begin{array}{l}\text { Admission from November } 2010 \text { to October } 2011 \text { using } \\
\text { configural frequency analysis of main diagnosis to } \\
\text { treatment settings decisions. There were } 2020 \text { referrals to } \\
\text { inpatients treatment with } 837 \text { outside the opening hours of } \\
\text { the unit for clinical decision making (UCDM). } 600 \\
\text { patients were seen in UCDM, } 589 \text { were hospitalized with } \\
\text { no UCDM exam }\end{array}$ & $\begin{array}{l}\text { Quantitative: using medical } \\
\text { databases of PDAG or } \\
\text { Psychiatric Services Aargu }\end{array}$ & $\begin{array}{l}\text { A specialized UCDM managed by clinical experts will } \\
\text { help identify cost effectiveness alternatives of psychiatric } \\
\text { hospitalization }\end{array}$ \\
\hline 3 & $\begin{array}{l}\text { Katsakou, Rose, Amo, } \\
\text { Bowers, McCabe, Oliver, } \\
\text { Wykes, Priebe, 2011, } \\
\text { United Kingdom }\end{array}$ & $\begin{array}{l}22 \text { involuntarily admitted patients underwent in-depth } \\
\text { face-to-face interview }\end{array}$ & $\begin{array}{l}\text { Qualitative: grounded theory, } \\
\text { thematic analysis }\end{array}$ & $\begin{array}{l}\text { Most of the patients felt mentally unwell before admission } \\
\text { and out of control during their treatment which is why some } \\
\text { patients view their involuntary hospitalisation positively, } \\
\text { whereas others believe it was wrong. This knowledge could } \\
\text { inform the development of interventions to improve } \\
\text { patients' views and treatment experiences. }\end{array}$ \\
\hline 4 & $\begin{array}{l}\text { McGarvey, Leon-Verdin, } \\
\text { Wancheck, Bonnie, 2013, } \\
\text { USA }\end{array}$ & $\begin{array}{l}\text { Face to face evaluation of individuals expressing mental } \\
\text { health crisis over a month in } 2007 \text { to a total of } 2,624 \text { adults. } \\
\text { It was performed by emergency services clinicians in } \\
\text { Virginia, USA using a questionnaire }\end{array}$ & $\begin{array}{l}\text { Quantitative: using } \\
\text { questionnaires }\end{array}$ & $\begin{array}{l}\text { A lack of intensive community based treatment and support } \\
\text { in lieu of hospitalization accounted for a significant portion } \\
\text { of variance in actions to initiate involuntary commitment. } \\
\text { Comprehensive community services and support for } \\
\text { individuals experiencing mental health crisis may reduce } \\
\text { the rate of involuntary hospitalization. }\end{array}$ \\
\hline 5 & Segal, 2011, USA & $\begin{array}{l}\text { State level data from online databases and key informant } \\
\text { surveys. Poisson regression and ordinary-least-squares } \\
\text { were used to evaluate the association between state } \\
\text { characteristics, mental health system characteristics and } \\
2004 \text { homicide rates after firearm control law was } \\
\text { implemented }\end{array}$ & $\begin{array}{l}\text { Quantitative: using } \\
\text { questionnaires: Poisson } \\
\text { regression and ordinary least } \\
\text {-squares }\end{array}$ & $\begin{array}{l}\text { Importance of broader involuntary civil commitment (ICC) } \\
\text { criteria, increased psychiatric inpatient bed access and } \\
\text { better performing mental health system as factors } \\
\text { contributing to homicide rate variation }\end{array}$ \\
\hline 6 & $\begin{array}{l}\text { Jendreyschack, Illess, } \\
\text { Hoffman, Holtman, Haas, } \\
\text { Burchard, Emons, Schaub, } \\
\text { Armgart, Schnider, Juckel, } \\
\text { Haussleiter, 2013, } \\
\text { Germany }\end{array}$ & $\begin{array}{l}\text { Regional cross sectional study through retrospective } \\
\text { analysis of hospital admission from three major German } \\
\text { Child and Adolescent Psychiatry (CAP) hospitals over a } \\
\text { period of six years from 2004-2009 involving 10,547 } \\
\text { patients }\end{array}$ & $\begin{array}{l}\text { Quantitative: group } \\
\text { comparison between } \\
\text { involuntarily and voluntarily } \\
\text { admitted minors and logistic } \\
\text { regression to determine } \\
\text { predictors of legal status }\end{array}$ & $\begin{array}{l}\text { Commitment laws and other legal instruments for } \\
\text { regulating involuntary placements are inconsistent and a } \\
\text { standardized description or systematic analysis is needed. } \\
\text { The influence of demographic, institutional variables and } \\
\text { care and health services aspects should also be investigated. }\end{array}$ \\
\hline 7 & $\begin{array}{l}\text { Myklebust, Sorgaard, } \\
\text { Wynn, 2014, Norway }\end{array}$ & $\begin{array}{l}5,538 \text { admissions in two specialist psychiatric service } \\
\text { areas in North Norway covering the periods } 2003-2006 \\
\text { focused on involuntary admissions using a logistic } \\
\text { regression model }\end{array}$ & $\begin{array}{l}\text { Quantitative: using data files } \\
\text { subjected to logistic } \\
\text { regression model }\end{array}$ & $\begin{array}{l}\text { Several factors predicted involuntary status including male } \\
\text { sex, the diagnosis and type of service system. The results } \\
\text { suggest that having psychiatric beds available locally may } \\
\text { be more favorable than a traditional deinstitutionalized } \\
\text { service system with local outpatient clinics and central } \\
\text { mental hospitals with respect to the use of involuntary } \\
\text { admission }\end{array}$ \\
\hline 8 & $\begin{array}{l}\text { Bola, Park, Kim, 2011, } \\
\text { South Korea }\end{array}$ & $\begin{array}{l}\text { International comparison of using a population based } \\
\text { metrics estimating the rates of involuntary admission in } \\
\text { South Korea per 100,000 people through an access to the } \\
\text { Korean Ministry of Health database on mental health } \\
\text { admissions }\end{array}$ & $\begin{array}{l}\text { Quantitative: using database } \\
\text { files and registry of patient } \\
\text { admissions }\end{array}$ & $\begin{array}{l}\text { Korea's involuntary admission is within the range of } \\
\text { European Union countries admission and three times higher } \\
\text { than the admission of the highest EU country which is } \\
\text { Sweden. The high proportion of admission in South Korea } \\
\text { is regarded to the underdevelopment of voluntary } \\
\text { psychiatric services and culturally mandated family } \\
\text { referrals }\end{array}$ \\
\hline 9 & $\begin{array}{l}\text { Wancheck, Bonnie, 2012, } \\
\text { USA }\end{array}$ & $\begin{array}{l}\text { Data from Virginia court system were matched to the } \\
\text { commonwealth of Virginia Medicaid claims database } \\
\text { from July 1,2008 to March 30,2009 with a final data set of } \\
500 \text { medicaid patients who had mental health diagnosis } \\
\text { and at least one temporary detention order (TDO) }\end{array}$ & $\begin{array}{l}\text { Quantitative: using database } \\
\text { files correlated to covariates } \\
\text { like sex, age, race, primary } \\
\text { diagnosis and community } \\
\text { service board serving the } \\
\text { individual }\end{array}$ & $\begin{array}{l}\text { Longer TDO periods were correlated with shorter hospital } \\
\text { stays and fewer involuntary commitments }\end{array}$ \\
\hline 10 & $\begin{array}{l}\text { Ducassee, Rene, Beziat, } \\
\text { Giullame, Courtet, Olie, } \\
\text { 2014, France }\end{array}$ & $\begin{array}{l}35 \text { outpatients suffering from Suicidal Behavior Disorder } \\
\text { (SBD) were assessed one week before the program and } \\
\text { one week and three months after the program completion. } \\
\text { Psychiatrist assessed suicidal ideation using Columbia } \\
\text { Suicide Severity Scale and the Scale for Suicidal Ideation } \\
\text { and also assessed the patients' psychiatric disorders using } \\
\text { the French version of the Mini International } \\
\text { Neurospsychiatric interview. Other disorders and test done } \\
\text { and assessed were Borderline Personality Disorder, } \\
\text { Depression, Global Assessment of Functioning and the } \\
\text { Pharmacological treatment and the number of visits in } \\
\text { psychiatric emergencies }\end{array}$ & $\begin{array}{l}\text { Quantitative: using scales and } \\
\text { questionnaires } \\
\text { Qualitative: using interview }\end{array}$ & $\begin{array}{l}\text { Adjunctive acceptance and commitment therapy group } \\
\text { programme could be effective for suicidality, to decrease } \\
\text { suicidal ideation in patients with SBD }\end{array}$ \\
\hline 11 & $\begin{array}{l}\text { Casella, Loch, 2014, } \\
\text { Brazil }\end{array}$ & $\begin{array}{l}\text { Sociodemographic data, data on the psychiatric disorder, } \\
\text { information about the hospital stay, and data at time of } \\
\text { discharge were collected from } 169 \text { individuals with } \\
\text { bipolar or psychotic disorder in need of hospitalization. } \\
\text { Their families were also contacted by telephone and } \\
\text { interviews were conducted at } 1,2,6 \text {, and } 12 \text { months } \\
\text { post-discharge as a follow-up. }\end{array}$ & $\begin{array}{l}\text { Quantitative: Prospective } \\
\text { observational study } \\
\text { Qualitative: telephone } \\
\text { interview }\end{array}$ & $\begin{array}{l}\text { Cultural factors related to religious affiliations might play } \\
\text { an important role in determining psychiatric hospitalization } \\
\text { legal status. Religion might possibly influence someone's } \\
\text { judgment and insight about his/her psychiatric disorder. } \\
\text { The study restates the importance of dealing with the } \\
\text { subject of religion with patients. }\end{array}$ \\
\hline 12 & $\begin{array}{l}\text { Nakhoust, Perry, Frank, } \\
\text { 2012, Canada }\end{array}$ & $\begin{array}{l}\text { All patients who were given Community Treatment } \\
\text { Orders or CTO during a nine year period admitted at } \\
\text { McGill University Hospital. The variables assessed were } \\
\text { number, duration, time to psychiatric admission, } \\
\text { comparing four time periods which are early, pre-index } \\
\text { (when the first CTOs was in force) and post-index }\end{array}$ & $\begin{array}{l}\text { Quantitative: naturalistic, } \\
\text { observational, retrospective, } \\
\text { before and after study }\end{array}$ & $\begin{array}{l}\text { CTOs are effective in assessing psychiatric patients with } \\
\text { histories of repeated hospitalizations to live and be treated } \\
\text { in the community diminishing the occurrence of frequent } \\
\text { hospitalizations }\end{array}$ \\
\hline
\end{tabular}

Still in USA, Valenti et al. ${ }^{[20]}$ enumerated perceptions of individuals on involuntary hospital treatment namely, lack of control in decision-making or loss of freedom, reduced risks as a benefit of involuntary treatment, and supportive working relationship between individual and staff. These perceptions display specific patient values namely, freedom, safety and respect, respectively. Alternately, staff values include upholding life and health. A similar study done in England, by 
Giacco and Priebe ${ }^{[21]}$ explored the association of suicidality and hostility among patients upon involuntary admission. They found out that one month after admission, 107 patients (5\% of assessed patients) had moderate or higher levels of suicidality while 97 patients $(5.2 \%)$ displayed consistent symptoms after three months. In terms of hostility, 307 $(14.5 \%)$ of the assessed patients had moderate or higher levels while there were 172 patients $(9.2 \%)$ after three months. With this trend, it can be seen that suicidality and hostility reduced over time. There were also other associated factors that may have affected the level of suicidality and hostility of the patients such as unemployment, etc.

Roggenbaum et al. ${ }^{[22]}$ found that after inpatient treatment and commitment, there is a great need for community mental health services for follow-ups and monitoring as evidenced by 169 deaths by suicide within one month after emergency commitment. There is an increase in the incidence of rehospitalization or subsequent hospital admissions and the length of stay among patients who were admitted involuntarily as observed in the trends of individuals with schizophrenia. As a predictor, they found that presence of job upon discharge help prevent relapse therefore help prevent rehospitalization. ${ }^{[23]}$ Bonnie $^{[24]}$ found out that the length of temporary detention order (TDO) periods is correlated with shorter duration of stay in the hospital and increased incidence of voluntary hospitalization as compared involuntary commitment. The longer the period of TDO, the shorter their hospital stay and lower incidences of involuntary commitment. TDO is done during the 48-hours period after individual experiences mental health crises for evaluation and emergency treatment. It was suggested that involuntary interventions be implemented considering the context of a recovery-oriented and patientcentered process to achieve goals rather than eliminating coercive measures and involuntary treatment which to an extent are effective. Also, informing the patient on the possible use of coercive measure should he/she display certain behaviors that require it actually decreases the perception of coercion. ${ }^{[13]}$

\subsubsection{Health system outcomes}

In the Scandinavian country of Norway, a decreased involuntary admission was associated with male sex, psychotic disorders and local health care system as evidenced by the decreased number of involuntary admissions with more available local beds. Myklebust, Sorgaard and Wynn ${ }^{[25]}$ explained that the proximity and local control of psychiatric beds and availability of psychiatric care in the local area help the individuals seek care and management before any worsening of condition occur. This also helps clinicians to more easily follow-up patients. The availability of community-based mental health services may reduce the number of involun-

Published by Sciedu Press tary inpatient treatment by engaging the individual in case management and treatment adherence program.

Wanchek and Bonnie ${ }^{[24]}$ found in their study on this that the increase in the availability of outpatient services is correlated with the increase in the use of such services which eventually lead to decrease in time of hospitalization. Since previous hospitalizations are great indicator of rehospitalization thus previous psychiatric hospitalization history is important information to help predict future need for treatment. Seemingly, it is the same scenario in the UK and England that the community or compulsory treatment orders (CTOs) are legal measures to help patients with severe mental illness to adhere or comply with treatment. These patients mainly have history of non-adherence to services and frequent hospitalizations due to certain behavior. This also ensures treatment adherence upon discharge of patients who were involuntary hospitalized. ${ }^{[26]}$ CTOs, under the setting of assertive community treatment, have posed positive outcomes as perceived by the patients. With CTO, patients receive assistance with housing and finances, there's a reduced social isolation and they are able to seek help voluntarily. ${ }^{[27]}$

In addition, they perceived that supportive relationship with the heath care team and the attitude of the members of the team could make significant difference in their perception of their treatment. CTOs are also revealed to be beneficial in catering to the increased number of patients being admitted amongst psychiatric patients. ${ }^{[19]}$ In Canada, the results of the study by Nakhost, Perry and Frank ${ }^{[28]}$ showed that when compulsory treatment was initiated, patients tend to stay out of hospital four times longer as compared to their early admission period as CTO facilitated treatment offer less restrictive conditions in contrast to psychiatric hospitals. It also suggested that CTO may improve outcomes when initiated for duration of six months or less and that it helps in reducing hospitalizations in psychiatric patients with histories of repeated admissions to hospitals.

Going back to Norway, however, Stuen et al. ${ }^{[27]}$ found out in their qualitative study that some patients who received involuntary treatment perceive that they don't have complete control of their lives, feeling that they are controlled by others. Also, the patients felt lack of influence towards their medication, that the care providers are the ones who decide for them and that there's coercion in this kind of treatment. On the contrary, some patients stated that CTO actually protects their legal rights and help them towards recovery. Therapeutic alliance with the health care providers actually affects their perception and feelings of resistance on their treatment. Building trust with the health care team helps them with their interaction and treatment adherence 
and alongside with it, as they build trust, negotiations and collaboration about the treatment plan becomes more significant and effective. ${ }^{[29]}$ However, upon systematic literature search by Segal et al., ${ }^{[30]}$ it was found out that there were no significant improvement in readmission, social functioning with the use of CTOs as compared with the standard care.

\subsubsection{Societal outcomes}

In a case in Switzerland, civil commitment does not only affect the individuals involved or the health care system, it also impacts the general society. Niklaus et al. ${ }^{[31]}$ explored in their study the effectiveness of UCDM in providing psychiatric treatment. Although $28(8 \%)$ of 338 cases that underwent UCDM examination but were not admitted to inpatient wards required hospitalization within four weeks upon referral and examination, the UCDM decisions for nonadmission of the other 310 patients proved to have provided cost savings for the facility as estimated. These 338 patients were either referred to day hospitals $(n=65)$ or outpatient care $(n=273)$ which had lower costs as compared to average treatment cost for inpatient treatment. In consideration of estimated personnel, overhead, operation and direct costs of the facilities involved in the study, an estimated overall cost savings of $€ 3.3$ million per year yielded upon the implementation of UCDM. ${ }^{[32]}$

In relation to this, assisted outpatient treatment (AOT) reduces total care costs in the areas covered as it shift the service provision from the repeated inpatient treatment to regular and improved outpatient care. The availability of AOT and its immediate management of mental health crisis, help prevent inpatient treatment which requires more expensive care. Comparing the relevant costs for patients on outpatient commitment and those who are not, Swartz and Swanson ${ }^{[33]}$ came to a conclusion that outpatient commitment specifically in North Carolina emerged to be cost-neutral and had savings of about $40 \%$.

In both countries of Canada and the USA in North America, AOT as a treatment promotes sense of autonomy in the midst of less restrictive environment. ${ }^{[34]}$ AOT helps in preventing arrests resulting from violence or other illegal actions among individuals who are enrolled in this service and among those who are not but are receiving care from the same clinic as those who are receiving AOT. ${ }^{[28,33,34]}$

In the city of New York, USA, particularly AOT was established under the Mental Health Law 9.6, known also as "Kendra's Law". Individuals undergoing AOT are assigned with a case manager and receive enhanced services such as housing and vocational services. Reviews on outpatient commitment reveal decreased frequency and duration of psychiatric hospitalizations as well as disruptive behaviors, and adherence to medication which is also consistent with the comprehensive reviews on AOT which states that it reduces suicidal tendencies, better social function and decreased violence. Upon analysis, the study showed that the risk of arrest is significantly higher among those who are not assigned in AOT. Considering this, outpatient commitment directly reduces crime and violence among these individuals making it an effective practice. However, more than the rate of arrests, there are other domains that are benefited by AOT such as personal welfare of the individual, etc. ${ }^{[33,34]}$ A related study by Segal ${ }^{[35]}$ explored on the association of involuntary civil commitment (ICC) and mental health system with dangerous behavior as evidenced by homicide rates.

In an American society, the results revealed that the three significant factors which are the mental health system indicators are associated with homicide rate variation. These are broader ICC criteria, increased psychiatric in-patient bed access, and better performing mental health systems. These accounted for $17 \%$ of the homicide rate variance. ${ }^{[36]}$ However, still, social-economic-demographic-geographic-and-political factors greatly influence homicide rates. Therefore, these three mental health system indicators should be reinforced and enhanced to protect the vulnerable population and this is contrary to the principal goals of civil commitment which is to achieve therapeutic and safety outcomes. ${ }^{[37]}$ One case in Florida, USA as revealed by the study of Robst, Constantine and Petrila, ${ }^{[3]}$ found that involuntary psychiatric examinations were associated with increases risk of arrest which showed individuals who were involuntarily examined were arrested in $34 \%$ of the quarters after examination while only $27 \%$ for those who did not undergo involuntary examination. This suggests that once an individual has been set or required for an involuntary examination, then this may indicate a higher risk of arrest in the near future.

\section{Conclusions}

Psychiatric commitment has posed challenges in the mental health system. Although its aim is to alleviate symptoms and prevent risks on the individual involved and others, there are potential risks in its practice. Involuntary commitment has displayed outcomes which may be beneficial at the same time detrimental to the patient. ${ }^{[37]}$ Many studies have been published that reported negative outcomes to patients receiving involuntary psychiatric commitment. Some of these negative outcomes include lower patient satisfaction, increased perception of coercion, increased re-hospitalization, dehumanization, and many others. Although this may be true, the aim of involuntary commitment was seen to be achieved by some studies in France where patients reported that indeed, they had needed such treatment otherwise, their condition 
will not improve. ${ }^{[38]}$

Not only does involuntary commitment affect patients, it also affects the health system such that there are several facilities wherein involuntary treatment may be done. In terms of societal outcomes, involuntary treatment is associated with homicide rate variation and the presence of outpatient treatment may decrease hospital costs as patients are already treated in the outpatient basis. ${ }^{[39]}$ It can be understood from the studies presented that outcomes of involuntary commitment were leaning more towards its risks on individuals but poses benefits on health system and society. ${ }^{[40]}$ However, in rendering health care, benefits should outweigh the risks and goals of treatment should be patient-centered and recovery-oriented. ${ }^{[41]}$ Therefore, more qualitative and quantitative studies focusing on benefits of psychiatric commitment should be conducted to weigh outcomes objectively. Also, analyzing the process of this intervention and the laws supporting it should be fully evaluated and should ensure rights of the individuals involved and be focused on reducing the risks accompanying this practice. ${ }^{[42]}$

\section{ACKNOWLEDGEMENTS}

The authors express their sincerest gratitude to the following persons and organizations, for without their help and assistance this study would not have been possible: the College of Nursing of the University of Hail $(\mathrm{UoH})$ and the whole $\mathrm{UoH}$ academic community, Hail city, Kingdom of Saudi Arabia; Dan Lorenz Tating and Ma. Leoant B. Santos of Nightingale Research Solutions; the editors at a professional editing service; and all who in one way or another made this study possible.

This study was funded by the Deanship of Scientific Research, College of Food and Agricultural Sciences, Research Center, King Saud University, Riyadh, Kingdom of Saudi Arabia.

\section{CONFlicts OF INTEREST Disclosure}

The authors declare they have no conflict of interest.

\section{REFERENCES}

[1] Priebe S, Katasakou C, Yeeles K, et al. Predictors of clinical and social outcomes following involuntary hospital admission: A prospective observational study. European Archives of Psychiatry and Clinical Neuroscience. 2011; 261: 377-386. PMid: 21181181. https://doi .org/10.1007/s00406-010-0179-x

[2] Lin-Ying H. Reconsidering the danger criterion in China's Mental Health Law: From an Ethical Perspective. Asian Bioethics Review. 2014; 6(2): 187-196. https://doi.org/10.1353/asb.2014.0 016

[3] Robst J, Constantine R, Petrila J. Association of involuntary psychiatric Examination with probability of arrest of people with serious mental illness. Psychiatric Services. 2011; 62: 1060-1065. PMid: 21885585. https://doi.org/10.1176/ps.62.9.pss6209_10 60

[4] Stulz N, Nevely A, Hilpert M, et al. Referral to inpatient treatment does not necessarily imply a need for inpatient treatment. Administration and Policy in Mental Health and Mental Health Services Research. 2014; 42(4): 474-483. PMid: 24898612. https: //doi.org/10.1007/s10488-014-0561-5

[5] Vinkers D, de Vries S, van Baars A, et al. Ethnicity and dangerousness criteria for court ordered admission to a psychiatric hospital. Social Psychiatry and Psychiatric Epidemiology. 2009; 45(2): 221224. PMid: 19396576. https://doi.org/10.1007/s00127-0 09-0058-9

[6] Slovenko R. Criminal law standards in civil commitment. Journal of Psychiatry \& Law. 2012; 40: 14-166. https ://doi.org/10.117 7/009318531204000205

[7] Rotvold K, Wynn R. Involuntary psychiatric admission: how the patients are detected and the general practiioners' expectations for hospitalization. An interview-based study. International Journal of Mental Health Systems. 2016; 10: 20. PMid: 26958076. https://doi.org/10.1186/s13033-016-0048-8
[8] Bola K, Park E, Kim S. Reassessing the high proportion of involuntary psychiatric hospital admissions in South Korea. Community Mental Health Journal. 2011; 47: 603-606. PMid: 21416122 https://doi.org/10.1007/s10597-011-9396-7

[9] Kaltiala-Heino R. Involuntary commitment and detainment in adolescent psychiatric inpatient care. Social Psychiatry and Psychiatric Epidemiology. 2009; 45(8): 785-793. PMid: 19690788. https: //doi.org/10.1007/s00127-009-0116-3

[10] Ran L. Ethical enquiry into the conditions under which involuntary commitment can be ethically justified. Asian Bioethics Review. 2014; 6(2): 174-186. https://doi.org/10.1353/asb.2014.0013

[11] Mills B. 'Paranoia, paranoia, everybody's coming to get me': Peep show, sitcom, and the surveillance society. Screen. 2008; 49(1): 5164. https://doi.org/10.1093/screen/hjn004

[12] Happell B, McAllister M, Gaskin C. Majors in mental health nursing: Issues of Sustainability and Commitment. Perspectives in Psychiatric Care. 2014; 51(1): 28-35. PMid: 24606586. https: //doi.org/10.1111/ppc.12063

[13] Geller J. Patient-centered, recovery-oriented psychiatric care and treatment are not always voluntary. Psychiatric Services. 2012; 63 : 493-495. PMid: 22549535. https://doi.org/10.1176/appi.p s. 201100503

[14] Whittemore R, Knafl L. The integrative review: updated methodology. Journal of Advanced Nursing. 2005; 52(5): 546-553. PMid: 16268861. https://doi.org/10.1111/j.1365-2648.2005.0 $3621 . x$

[15] Katasakou C, Rose D, Amos T, et al. Psychiatric patients' views on why their involuntary hospitalization was right or wrong: A qualitative study. Social Psychiatry and Psychiatric Epidemiology. 2011; 47: 1169-1179. PMid: 21863281. https://doi.org/10.1007/s001 27-011-0427-z

[16] Jendreyschak J, Illes F, Hoffmann K, et al. Voluntary versus involuntary hospital admission in child and adolescent psychiatry: a German 
sample. European Child \& Adolescent Psychiatry. 2013; 23(3): 151161. PMid: 23793531. https ://doi.org/10.1007/s00787-013 -0440-8

[17] Casella C, Loch A. Religious Affiliation as a Predictor of Involuntary Psychiatric Admission: A Brazilian 1-Year Follow-Up Study. Frontiers in Public Health [Internet]. 2014 [cited 7 March 2017]. Available from: https://www.ncbi.nlm.nih.gov/pmc/articles/PMC4 $127467 /$

[18] McNiel D, Gormley B, Binder R. Leverage, the treatment relationship and treatment participation. Psychiatric Services. 2013; 64(5): 431-436. PMid: 23412399. https://doi.org/10.1176/appi.p s. 201200368

[19] Sheehan K, Burns T. Perceived coercion and the therapeutic relationship: A neglected association?. Psychiatric Services. 2011; 62(5): 471-476. PMid: 21532071. https://doi.org/10.1176/ps.62. 5.pss6205_0471

[20] Valenti E, Giacco D, Katasakou C, et al. Which values are important for patients during involuntary treatment? A qualitative study with psychiatric inpatients. J Med Ethics. 2014; 40: 832-836. PMid: 24129367. https://doi.org/10.1136/medethics-2011-100 370

[21] Giacco D, Priebe S. Suicidality and hostility following involuntary hospital Ttreatment. Plos One. 2016; 11(5): e0154458. PMid: 27171229. https://doi.org/10.1371/journal.pone.01544 58

[22] Roggenbaum S, Christy A, LeBlanc A. Suicide assessment and prevention during and after emergency commitment. Community Mental Health Journal. 2011; 48: 741-745. PMid: 21681457. https : //doi.org/10.1007/s10597-011-9428-3

[23] Pfiffner C, Steinert T, Kilian R, et al. Re-hospitalization risk of former voluntary and involuntary patients with schizophrenia. Social Psychiatry and Psychiatric Epidemiology. 2014; 49: 1719-1727. PMid: 24806950. https://doi.org/10.1007/s00127-014-0892-2

[24] Wanchek T, Bonnie R. Use of longer periods of temporary detention to reduce mental health civil commitments. Psychiatric Services. 2012; 63(70): 643-648. PMid: 22588149. https://doi.org/10 .1176/appi.ps. 201100359

[25] Myklebust L, Sorgaard K, Wynn R. Local psychiatric beds appear to decrease the use of involuntary admission: A case-registry study. BMC Health Services Research. 2014; 14(64): 1-7. https : //doi.org/10.1186/1472-6963-14-64

[26] Sharma V. Community treatment orders - principles and attitudes: Commentary on... Community treatment orders: Current practice and a framework to aid clinicians. The Psychiatrist. 2013; 37(2): 58-59. https://doi.org/10.1192/pb.bp.112.040170

[27] Stuen H, Rugkasa J, Landheim A, et al. Increased influence and collaboration: A qualitative study of patients' experiences of community treatment orders within an assertive community treatment setting. BMC Health Services Research. 2015; 15: 409. PMid: 26400028. https : //doi .org/10.1186/s12913-015-1083-x

[28] Nakhost A, Perry J, Frank D. Assessing the outcome of compulsory treatment orders on management of psychiatric patients at two McGill University-associated hospitals. The Canadian Journal of Psychiatry. 2012; 15(6): 359-365.
[29] Jethwa K. Challenges and opportunities in (neuro)psychiatry. Psychiatric Bulletin. 2014; 38(5): 251-252. PMid: 25285229. https : //doi.org/10.1192/pb.38.5.251a

[30] Segal S, Preston N, Kisely S, et al. Conditional release in Western Australia: Effect on hospital length of stay. Psychiatric Services. 2009; 60(1): 94-99. PMid: 19114577. https ://doi.org/10.117 $6 / \mathrm{ps} .2009 .60 \cdot 1.94$

[31] Stulz N. Patientenorientierte Psychotherapieforschung. PRAXIS. 2016; 105(23): 1371-1374. https://doi:http://dx.doi.org /10.1024/1661-8157/a002524

[32] Referral to inpatient treatment does not necessarily imply a need for inpatient treatment [Internet]. Research gate. 2017 [cited 3 February 2017]. Available from: https ://www.researchgate.net/publication/26288 4442_Referral_to_Inpatient_Treatment_Does_not_Nece ssarily_Imply_a_Need_for_Inpatient_Treatment

[33] Swanson JW, Elizabeth MGE, Seena F, et al. Mental illness and reduction of gun violence and suicide: bringing epidemiologic research to policy. Annals of Epidemiology. 2015; 25(5): 366. PMid: 24861430. https://doi.org/10.1016/j.annepidem.2014.03.004

[34] Kendra's Law overview. Available from: http://mentalillnes spolicy.org/kendras-law/kendras-law-overview.html

[35] Dus A. "But I'm not dangerous, judge, I promise!": Evaluating the implications of involuntary civil commitment criteria and outpatient treatment methods on the elderly. The Elderly Law Journal. 2016; 23 : 453-488.

[36] Segal S. Civil commitment law, mental health services and US homicide rates. Social Psychiatry and Psychiatric Epidemiology. 2011; 478: 1449-1458.

[37] Broader commitment lowers homicide rates [Internet]. Available from: http://mentalillnesspolicy.org/national-studi es/commitmenthomiciderates.html

[38] Menninger J. Involuntary treatment: Hospitalization and medications. 2017. Available from: http://www.brown.edu/Courses/BI_2 78/Other/Clerkship/Didactics/Readings/INVOLUNTARY\% 20TREATMENT.pdf

[39] Gourevitch R, Brichant-Petitjean C, Crocq M, et al. The evolution of laws regulating psychiatric commitment in France. Psychiatric Services. 2013; 64: 609-612. PMid: 23821167. https : //doi.org/10.1176/appi.ps. 201300174

[40] Link B, Epperson M, Perron B, et al. Arrest outcomes associated with outpatient commitment in New York state. Psychiatric Services. 2011; 62: 504-508. PMid: 21532076. https ://doi .org/10.117 6/ps.62.5.pss6205_0504

[41] Rugkasa J. Effectiveness of community treatment orders: The international evidence. The Canadian Journal of Psychiatry. 2016; 61(1): 15-24. PMid: 27582449. https://doi.org/10.1177/07067437 15620415

[42] Stulz N, Nevely A, Hilpert M, et al. Referral to Inpatient Treatment Does not Necessarily Imply a Need for Inpatient Treatment. Administration and Policy in Mental Health and Mental Health Services Research. 2015; 42(4): 474. PMid: 24898612. https: //doi.org/10.1007/s10488-014-0561-5 